\title{
Calculation of the Profile of a Horizontally Branched Well
}

\author{
Nurlan Aldamzharov ${ }^{1}$, Bayan Almatova ${ }^{2}$, Fatyma Balmaganbetova ${ }^{3}$, Dameli Uteulieva ${ }^{4}$, Saltanat Dauletova ${ }^{5}$, \\ Bakutgyl Toksanbaeva ${ }^{6}$ \\ ${ }^{1}$ Technological Park “Zerek”; Department of Oil, Gas and Mining, Baishev University, Kazakhstan, e-mail: \\ aldamzharov_n@mail.ru \\ ${ }^{2}$ Department of Oil and Gas, Baishev University, Kazakhstan \\ ${ }^{3}$ Department of Technical Cybernetics, Baishev University, Kazakhstan \\ ${ }^{4}$ Department of Agriculture and Ecology, Baishev University, Kazakhstan \\ ${ }^{5}$ Department of Oil, Gas and Mining, Baishev University, Kazakhstan \\ ${ }^{6}$ Department of Technical Cybernetics, Baishev University, Kazakhstan
}

\begin{abstract}
This article provides a calculation of the profile, which, at a given radius of curvature, ensures the required zenith angle of multilateral wells of a horizontally branched section at the required depth, the lengths and projections of other characteristic profile sections, the coordinates of the end points of the branches and the values of the zenith angle and azimuth in them when drilling along a given radius. The relevance of the research lies in the development of recommendations for the use of horizontally branched wells in the construction of oil and gas wells, taking into account the geological features and the influence of technological and technical factors in the penetration with horizontal and multilateral wells. Calculations make it possible to choose a well drilling technology that provides maximum development profitability and a reliable, stable operation of the selected wells without complications. Based on calculations conducted, it is concluded that horizontal wells are efficient if the formation is uniform or almost uniform in terms of permeability. In order to reduce the influence of uniformly impermeable formations, it is recommended to drill horizontally branched wells. When drilling a well with horizontal endings with the zenith angles of 85-90 degrees, the configurations of the well axis in the branch sections are circular arcs with a decrease or increase in the zenith angle in planes different from the apsidal plane of a horizontally branched section.
\end{abstract}

Key words: Length of a horizontally branched section, inclinometry, design profile of a multilateral well, zenith angle, zenith angle increase

\section{INTRODUCTION}

The current stage of production drilling is characterized by a transition from the practice of laying individual wells to the system of developing oil and gas fields with wells.

The optimization of oil and gas recovery should be based on the development of knowledge about the structure of productive formations and the movement of fluids in combination with horizontal and multilateral wells systems. The features of the geological structure of oil and gas fields can be determined by combining the data obtained as a result of seismic work, geophysical and hydrodynamic studies during well construction, and probabilistic modeling of the formation. Moreover, the efficiency of horizontal and multilateral wells systems depends on the consistent and adequate application of the source information at the design and implementation stages.

Taking into account the prospects of this direction, the present work analyzes the efficiency of the construction of multilateral wells [1].

In order to avoid the undesirable consequences of well curvature, one should know the causes and patterns of curvature, as well as ensure that wells are installed in a given direction. There is also a need to know the laws of curvature for the implementation of artificial well deviation. It makes it possible to avoid the laying of wells with inclined boreholes and to strike the productive horizon at several points from one main borehole.

The basic principles of drilling directional and horizontal wells served as the basis for the development of a method of the multilateral drilling of productive formations, providing a many-fold expanded drainage zone and a filtration surface in the productive formation. This method is also used when drilling additional boreholes to extend the life of the production well.

In 1953, A.M. Grigoryan in cooperation with Yu.P. Borisov addressed some basic theoretical issues in the construction of multilateral wells [3].

The considered works give the definition of a multilateral well as a complex object of industrial construction, describe the main characteristics of oil fields, for which it is necessary and expedient to construct multilateral wells, as well as highlight the types of profiles of these wells for various geological and technical conditions and characteristics of productive formations.

The foundations of domestic technology for drilling deep horizontal wells in Kazakhstan were laid in the 2000s (Zhanazhol field, Aktobe region) [2].

The analysis of the operation of horizontal wells shows that the creation of multilateral wells, and, as a special case, horizontally branched wells, is one of the ways to increase oil 
recovery in unproductive formations and deposits in hard-toreach shelf areas and conservation zones [3].

The main reasons for the relatively low efficiency of multilateral wells are as follows:

- $\quad$ incorrectly selected profiles of multilateral wells;

- non-compliance with the design profile and the multilateral well structure, inaccuracy of getting multilateral wells in productive formations;

- $\quad$ poor-quality development of multilateral well boreholes due to the lack of reliable penetration methods;

- insufficient tightness in the zones of multilateral well branches and lack of the possibility of borehole separation for selective impact on the formation [5].

Currently, there is a methodology for calculating the design profiles of horizontal wells of various types. These include profiles with a rectilinear horizontal section in the productive horizon, profiles with a low-intensity increase and decrease in the zenith angle in the productive horizon, as well as profiles with a sinusoidal section of the well borehole in the productive horizon [6]. Methodological foundations for calculating profiles and designing multilateral wells, which would cover the whole variety of mining-geological and operational conditions, have not yet been developed [7]. One of the most important tasks is to create a computerized spatial module and software for the design and management of multilateral wells [8].

The purpose of the study is to improve technological methods for drilling deep horizontally branched wells and to prevent negative curvature during drilling, providing quality and a significant increase in drilling productivity [9].

The work provides a calculation of the profile, which, at a given radius of curvature, ensures the required zenith angle of multilateral wells of a horizontally branched section at the required depth, the lengths and projections of other characteristic profile sections, the coordinates of the end points of the branches and the values of the zenith angle and azimuth in them when drilling along a given radius [10-12].

\section{RESULTS AND DISCUSSION}

The calculation includes the following key provisions:

- the variety of types of the profiles of multilateral wells can be reduced to a generalized profile containing the characteristic sections of these profiles, the calculation of which is uniform for all these types of profiles;

- the design profile of a multilateral well is generally spatial in nature;

- a generalized profile (Figure 1) consists of the following sections:

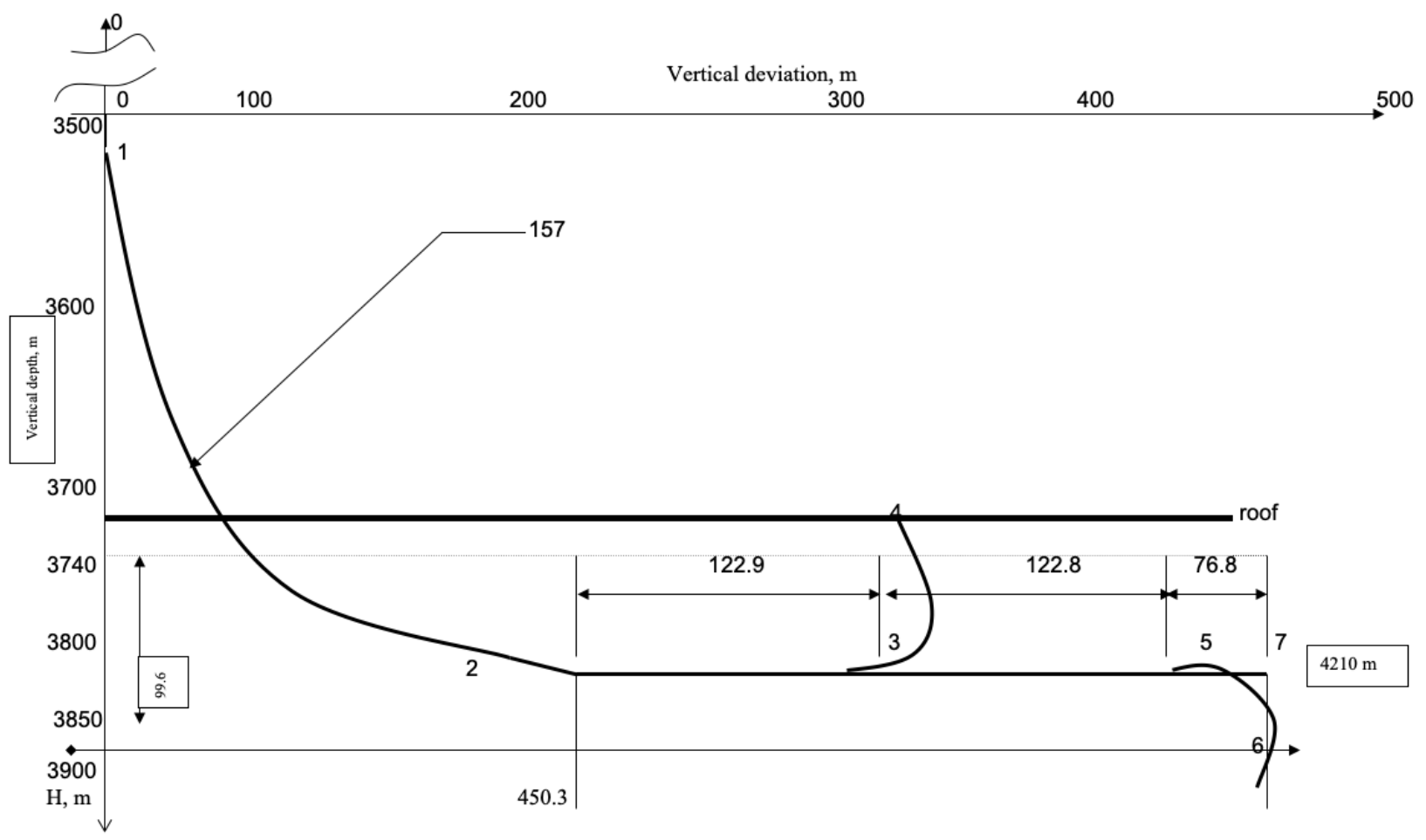

Figure 1: Design profile of the section of an increase and horizontally branched stabilization of the zenith angle

○ vertical (0-1);

0 an increase in the zenith angle along the radius $\mathrm{R}-157 \mathrm{~m}(1-2)$;

- a horizontally branched section of the stabilization of the zenith angle (2-7);

- sections of the branches of horizontally branched boreholes (3-4, 5-6);

- configurations of the well axis in the branch sections are circular arcs with a decrease or increase in the zenith angle in planes different from the apsidal plane of a horizontally branched section; 
- calculation of the profile is reduced to determining the length of the vertical section, which, at a given radius of curvature, ensures the required zenith angle of multilateral wells of a horizontally branched section at the required depth, the lengths and projections of other characteristic profile sections, the coordinates of the end points of the branches and the values of the zenith angle and azimuth in them when drilling along a given radius.

The initial data for designing a well profile include:

- the vertical depth of the beginning of the horizontal section Нг, $\mathrm{m}-3740$;

- the radius of an increase in the zenith angle in the second section $\mathrm{R}, \mathrm{m}-157$;

- $\quad$ the zenith angle $\alpha \Gamma$, degree - 72;

- $\quad$ the azimuthal angle $\varphi \Pi$, degree -85 ;

Table 1: Calculation of the lengths and projections of the characteristic profile sections

\begin{tabular}{|c|c|c|c|}
\hline Section & $\begin{array}{c}\text { Borehole length, } \\
m\end{array}$ & $\begin{array}{l}\text { Horizontal projection } \\
\qquad\end{array}$ & $\begin{array}{l}\text { Vertical projection } \\
m\end{array}$ \\
\hline 1 & 2 & 3 & 4 \\
\hline Vertical (0-1) & $H_{\Gamma}-R \sin \alpha_{\Gamma}=3561.6$ & $H_{s}=H_{\mathrm{\Gamma}}-R \sin \alpha_{\mathrm{\Gamma}}=3561.6$ & \\
\hline $\begin{array}{l}\text { Zenith angle } \\
\text { increase (1-2) }\end{array}$ & $0.01745 R \alpha_{\Gamma}=197.25$ & $H_{a}=\left(1-\cos \alpha_{\Gamma}\right) R=108.5$ & $S_{n t p}=R \sin \alpha_{\mathrm{T}}=149.3$ \\
\hline $\begin{array}{l}\text { Horizontal } \\
\qquad \begin{array}{c}(2-7) \\
2-3 \\
3-4 \\
3-5 \\
5-6 \\
5-7\end{array}\end{array}$ & $\begin{array}{l}L=322.5 \\
S_{o}=122.9 \\
0.01745_{\text {Г1 } 11}=24.4 \\
S_{1}=122.8 \\
0.01745_{\text {Г1 } 11}=26.1 \\
S_{2}=76.8\end{array}$ & $\begin{array}{l}H_{\Gamma} L \cos \alpha_{\Gamma}=99.6 \\
S_{\Gamma 0}=S o \cos \alpha_{\Gamma}=37.9 \\
h_{\Gamma 1} \sin \alpha_{\Gamma}=47.5 \\
S_{\Gamma 1}=S_{1} \cos \alpha_{1}=37.9 \\
h_{\Gamma 2} \sin \alpha_{\Gamma}=42.79 \\
S_{\Gamma 2}=S_{2} \cos \alpha_{\Gamma}=23.7\end{array}$ & $\begin{array}{l}A_{\Gamma}=L \sin \alpha_{\Gamma}=306.7 \\
S_{n o}=S_{o} \sin \alpha_{\Gamma}=116.8 \\
S_{n 1}=122.8 \\
S_{1} \sin \alpha_{\Gamma}=116.8 \\
S_{n 2}=61.4 \\
S_{2} \sin \alpha_{\Gamma}=73.1\end{array}$ \\
\hline
\end{tabular}

- $\quad$ the length of the horizontally branched section L, m 450.3;

- the distance between the start of spudding the branches along the length of the horizontal borehole $\mathrm{Si}, \mathrm{m}$ $(\mathrm{S} 1=122.8 ; \mathrm{S} 2=76.8)$;

- displacements of the end of the branch sections relative to the conventionally horizontal section of the borehole in the vertical hri, $\mathrm{m}-(\mathrm{hr} 1=47.5 ; \mathrm{hr} 2=42.7)$ and horizontal planes hni, $\mathrm{m}$ - (hn1=55; hn2=53);

- the radiuses of branch curvature $\mathrm{ri}-(\mathrm{r} 1=\mathrm{r} 2=)$.

Table 1 shows the calculation of the lengths and projections of the characteristic sections of the profiles. The following notation is used here: Sni is the horizontal projection length of the corresponding branch, $\mathrm{m}-(\mathrm{Sn} 1=61.4 ; \mathrm{Sn} 2=122.8)$.

According to the calculation, we obtain:

$$
\text { Snn }=\sqrt{\kappa_{i}\left(2 r_{i}-k_{i}\right) \sin \alpha_{r}}=\sqrt{3990}=63.2 \text {; }
$$

$$
k=\sqrt{h^{2} r_{i}+h^{2} r} i=\sqrt{45,2+54}=\sqrt{4959}=70.4 \text {; }
$$

where, $\gamma \mathrm{i}$ is the angle of coverage of the corresponding branch, degrees,

$\gamma_{i}=\operatorname{arctq} \sqrt{\frac{k_{i}\left(2 r_{i}-k_{i}\right)}{r_{i}-k_{i}}}$ $\gamma=\operatorname{arctq} \sqrt{70.4 \frac{(2 \times 65-70.4)}{2 \times 65-70.4}}=\operatorname{arctq} \sqrt{140.8}=\operatorname{arctq} 11.9=0.211=1 \backslash 0.211=4.74$

Table 2 shows the formulas for calculating the zenith angles and azimuths at the end of various branches of the horizontally branched borehole, where the following notation is used $[4,13]$ :

I, p, m are auxiliary coefficients;

$\Pi$ is the vertical laying;

$\mathrm{d}$ is the horizontal laying;

$\mathrm{q}$ is the length of the branched borehole.

$I=\frac{k(r-k)}{\sqrt{k(2 r x k)}}=\frac{70.4(70-70.4)}{\sqrt{70.4(2 \times 70-70.4)}}=0.71 ;$

(4)

$p=\sqrt{g^{2}-d^{2}}=\sqrt{9.8^{2}+0.215^{2}}=9.8 ;$

$m=\sqrt{k(2 r-k)}=\sqrt{70.4(2 \times 70-70.4)=69.9} ;$

(6)

where, $\alpha \Gamma$ is the zenith angle of the horizontally branched borehole, rad;

$\mathrm{r}$ is the radius of branch curvature, $\mathrm{m}$;

$\mathrm{h} \Gamma$ is the branch displacement relative to the horizontally branched borehole in the vertical plane, m;

$\mathrm{h} \Pi$ is the branch displacement relative to the horizontally branched borehole in the horizontal plane, $\mathrm{m}$; $\varphi п$ is the design azimuth, rad.

\begin{tabular}{|c|c|c|c|c|c|}
\hline $\begin{array}{l}\text { Bra } \\
\text { nch } \\
\text { type }\end{array}$ & \begin{tabular}{c|} 
Zenith \\
angle at \\
the end \\
of the \\
section, \\
rad
\end{tabular} & $n, m$ & $q, m$ & $d, m$ & $\begin{array}{c}\text { Azimuth at the } \\
\text { end of the section, } \\
\text { rad }\end{array}$ \\
\hline 1 & 2 & 3 & 4 & 5 & 6 \\
\hline & $\begin{array}{l}\frac{\pi}{2}+\operatorname{arctq} \\
\frac{n}{\rho}=0.226\end{array}$ & $\begin{array}{l}h_{\mathrm{T}_{1}} \sin \alpha_{\mathrm{r}} \\
=47.5\end{array}$ & $\begin{array}{l}\frac{h_{n}+h_{n} \mathrm{I} \cos \alpha_{\mathrm{r}}}{h_{\mathrm{r}} \sin \alpha_{\mathrm{r}}-\mathrm{I} \cos \alpha_{\mathrm{r}}} \\
=55.3\end{array}$ & $\begin{array}{l}\mathrm{I}\left(\frac{h_{\mathrm{r}} \cos \alpha_{\mathrm{\Gamma}}+\mathrm{I}}{h_{\mathrm{r}}-\mathrm{I} \operatorname{ctg} \alpha_{\mathrm{r}} x \cos \alpha_{\mathrm{r}}+\sin \alpha_{\mathrm{r}}}\right) \\
+h_{\mathrm{r}} \cos \alpha_{\mathrm{r}}=16.4\end{array}$ & $\begin{array}{l}\varphi=\varphi_{m}-\operatorname{arct} q \\
\frac{q}{d}=0.117\end{array}$ \\
\hline & $\begin{array}{l}\frac{\pi}{2}-\operatorname{arctq} \\
\frac{n}{\rho}=0.157\end{array}$ & $\begin{array}{l}h_{\mathrm{T} 1} \sin \alpha_{\mathrm{r}}+ \\
m \cos =62\end{array}$ & $\begin{array}{l}\frac{h_{n}+h_{n}(m-1) \cos \alpha_{\mathrm{r}}}{h_{\mathrm{r} 1} \sin \alpha_{\mathrm{r}}+\mathrm{I} \cos \alpha_{\mathrm{r}}} \\
=79.3\end{array}$ & $\begin{array}{l}\mathrm{I}\left(\frac{h_{\mathrm{r}} \operatorname{ctg} \alpha_{\mathrm{r}}+\mathrm{I}}{h_{\mathrm{r}}-\mathrm{I} c t q \alpha_{\mathrm{r}}} \cos \alpha_{\mathrm{r}}+\sin \alpha_{\mathrm{r}}\right) \\
+h_{\mathrm{r}} \cos \alpha_{\mathrm{r}}=15.1\end{array}$ & $\begin{array}{l}\varphi=\varphi_{m}+\operatorname{arctq} \\
\frac{q}{d}=0.104\end{array}$ \\
\hline
\end{tabular}

Table 2:Angular parameters of multilateral well branches

The relevance of conducted studies consists in the development of recommendations for the use of horizontally branched wells in the construction of oil and gas wells, taking into account the geological features and the influence of technological and technical factors in the penetration with horizontal and multilateral wells.

Calculations make it possible to choose a well drilling technology that provides maximum development profitability and a reliable, stable operation of the selected wells without complications.

The results obtained in the work can be used in drilling wells of the horizontally branched borehole with similar geological and field characteristics. 


\section{CONCLUSION}

The above calculations make it possible to draw the following conclusions and suggestions:

- Horizontal wells are efficient if the formation is uniform or almost uniform in terms of permeability;

- In order to reduce the influence of uniformly impermeable formations, it is recommended to drill horizontally branched wells.

When drilling a well with horizontal endings with the zenith angles of 85-90 degrees, the configurations of the well axis in the branch sections are circular arcs with a decrease or increase in the zenith angle in planes different from the apsidal plane of a horizontally branched section.

\section{REFERENCES}

1. A.S. Oganov.Multilateral well drilling development, problems and progress. Moscow, JSC "VNIIOENG", 2001.

2. N.N. Aldamzharov.Designing the technology of horizontally branched wells at the Zhanazhol field.Oil and gas business. Aktobe, 2003.

3. A.M. Grigoryan.Horizontally branched wells as the near future of the oil industry. Moscow: Neftyanoyekhozyaystvo, 2007.

4. A.G. Kalinin and B.A. Nikitin.Inclined and horizontal wells. Moscow: Nedra, 2008.

5. A.G. Kalinin, B.A. Nikitin, K.M. Solodky and B.Z. Sultanov.Drilling of inclined and horizontal wells. Moscow: Nedra, 2007.

6. N.N. Aldamzharov.Horizontal well construction at the Zhanazhol field, in V International Symposium on Drilling Wells under Complicated Conditions. St. Petersburg, June 11-15, 2001, pp. 5-6.

7. N.N. Aldamzharov, M.Zh. Muzaparov and A. Tursyn, Factors affecting oil production at the Zhanazhol field.Oil Gas J., Vol. 3, pp. 53-57, 2007.

8. N.N. Aldamzharov, M.Zh. Muzaparov and A. Tursyn.Analysis of the exploitation of horizontal wells at the Zhanazhol field.Oil Gas J., Vol. 3, pp. 63-70, 2007.

9. C.K. Yee and K.S. Yen. Simplified Geometric Model for Generic Projector Application.Int. J. Adv. Trends Comp. Sc. Eng., Vol. 9, No. 1, pp. 116-123, 2020. https://doi.org/10.30534/ijatcse/2020/18912020

10. S. Byun. Gateway-based Resource Control for Reliable IoT Environments.Int. J. Adv. Trends Comp. Sc. Eng., Vol. 8, No. 5, pp. 1881-1885, 2019. https://doi.org/10.30534/ijatcse/2019/11852019

11. G.G. Kalach and G.P. Kalach. Navigation System Based on the Fuzzy Logic Expert System.Int. J. Adv. Trends Comp. Sc. Eng., Vol. 8, No. 6, pp. 2693-2698, 2019. https://doi.org/10.30534/ijatcse/2019/02862019

12. V.A.Khomyakov, Y.M.Shokbarov and A.A. Bryantsev.Experience in Handling Differential Settlements of Multi-Storey Buildings on Soft Soil.Soil Mech.Found.Eng., Vol. 54, No. 5, pp. 330335,2017. https://doi.org/10.1007/s11204-017-9477-x

13. V.A.Khomyakov, E.E.Iskakov and E.T.Serdaliev .Investigation of gravelly soil during underground construction in Almaty.Soil Mech.Found. Eng., Vol. 50, No.4, pp. 171-177, 2013.

https://doi.org/10.1007/s11204-013-9230-Z 